\title{
Detection of K-ras mutations in non-small cell lung carcinoma
}

\author{
E.M. NEVILLE ${ }^{1}$, G. ELLISON ${ }^{2}$, H. KIARIS ${ }^{1,3}$, M. STEWART ${ }^{1}$, D.A. SPANDIDOS ${ }^{3,4}$, J.C. FOX ${ }^{2}$ and J.K. FIELD ${ }^{1}$ \\ ${ }^{1}$ Molecular Genetics and Oncology Group, Department of Clinical Dental Sciences, University of Liverpool, L69 3BX, UK; \\ ${ }^{2}$ Zeneca Diagnostics, Research and Development Group, Gadbrook Park, Northwich, Cheshire, CW9 7RA, UK \\ ${ }^{3}$ National Hellenic Research Foundation, Institute of Biological Research and Biotechnology, Athens 116 35, Greece; \\ ${ }^{4}$ Medical School University of Crete, Heraklion 71100, Greece;
}

Contributed by D.A. Spandidos, June 14, 1995

\begin{abstract}
Forty-five non-small cell lung cancers (NSCLC) were examined for the presence of $\mathrm{K}$-ras mutations in codon 12 using RFLP (restriction fragment length polymorphism) and ARMS (amplification refractory mutation system) assays. The RFLP analysis consisted of a PCR and subsequent digestion of the product with BstNI. Three adenocarcinomas and one adenosquamous carcinoma were shown to have mutations at codon 12. All of these samples were also examined using the ARMS assay for mutations at codon 12 and second base $\mathrm{G}$ to A transitions at codon 13 of the K-ras gene. The same four samples were confirmed to have a single base change in codon 12 . No G to A transitions were found at codon 13. The four mutations were: one $\mathrm{G}$ to $\mathrm{C}$ transversion, one $\mathrm{G}$ to $\mathrm{A}$ transition and two $\mathrm{G}$ to $\mathrm{T}$ transversions. All mutations occurred at the second position of codon 12 as shown by the ARMS assay. Both of these techniques are rapid and reproducible for the identification of mutations in the K-ras gene and have potential for use in cancer diagnosis.
\end{abstract}

\section{Introduction}

Lung cancer is one of the most prevalent malignancies in the world (1). Rapid and reproducible methods for the unambiguous detection of molecular lesions in lung cancer at an early stage could have great impact on the survival and treatment of lung cancer patients. The ras family of oncogenes include three closely related genes $\mathrm{H}$-ras, $\mathrm{N}$-ras and $\mathrm{K}$-ras. These genes encode highly conserved 21-kiloDalton $(\mathrm{kD})$ proteins that functionally resemble G-proteins and appear to be involved in signal transduction and cell cycle control. To date, mutations in these genes have been the most frequently observed genetic lesions in a number of human malignancies (2). In animal models it has been shown that ras mutations are an early event and have been demonstrated to precede neoplastic growth (3).

Correspondence to: Dr J.K. Field, Department of Clinical Dental Sciences, The University of Liverpool, Liverpool, L69 3BX UK

Key words: K-ras mutations, lung tumours, (ARMS) amplification refractory mutation system
This also appears to be the case in some human carcinomas, particularly carcinomas of the colorectum. Mutated ras oncogenes are found in benign and malignant neoplasms of the colorectum at approximately the same frequency. Similar mutations have been found in premalignant colon tissue adjacent to colorectal carcinomas thereby indicating a genetic progression of the disease (4). In head and neck cancer, overexpression of the ras gene has been associated with a favourable prognosis and may be considered to play a role in the early development of the disease $(5,6)$. Taken together, these findings suggest that ras mutations are an early event in the development of neoplasia.

A high frequency of K-ras mutations have been detected in many forms of cancer including pancreatic cancers (90\%), colorectal tumours $(50 \%)$, thyroid carcinomas $(30 \%)$ and about one third of non-small cell lung cancers (NSCLC) (2). The most common point mutations found in NSCLC are in the K-ras gene with the majority (up to $93 \%$ ) occurring in codon 12 (7).

In this study 45 NSCLC were analysed by two detection systems: a PCR, restriction fragment length polymorphism assay (PCR RFLP, 8) detecting mutations of codon 12 in K-ras and the ARMS assay (amplification refractory mutation system, 9) which was used to identify specific base changes leading to any potential non-silent codon 12 mutations and the $\mathrm{G}$ to A glycine to aspartic acid codon 13 transition.

\section{Materials and methods}

Sample collection. Forty-five NSCLC were obtained from patients undergoing lung resection for bronchial tumours presenting to the Cardiothoracic Centre of the Liverpool NHS trust. After resection the tumours were snap frozen. There were 15 adenocarcinomas, 7 adenosquamous, 18 squamous, 3 large cell, 1 neuroendocrine, 1 sarcomatoid carcinoma.

DNA extraction. High molecular weight genomic DNA was prepared from tumour tissue as previously described (6) using the Nucleon II DNA extraction kit (Scotlab) following the manufacturers instructions. Genomic DNA samples were stored at $4^{\circ} \mathrm{C}$.

PCR amplification and restriction enzyme analysis. PCR amplification and restriction of the product were carried out using the primers and protocol described by Jiang et al (8). 

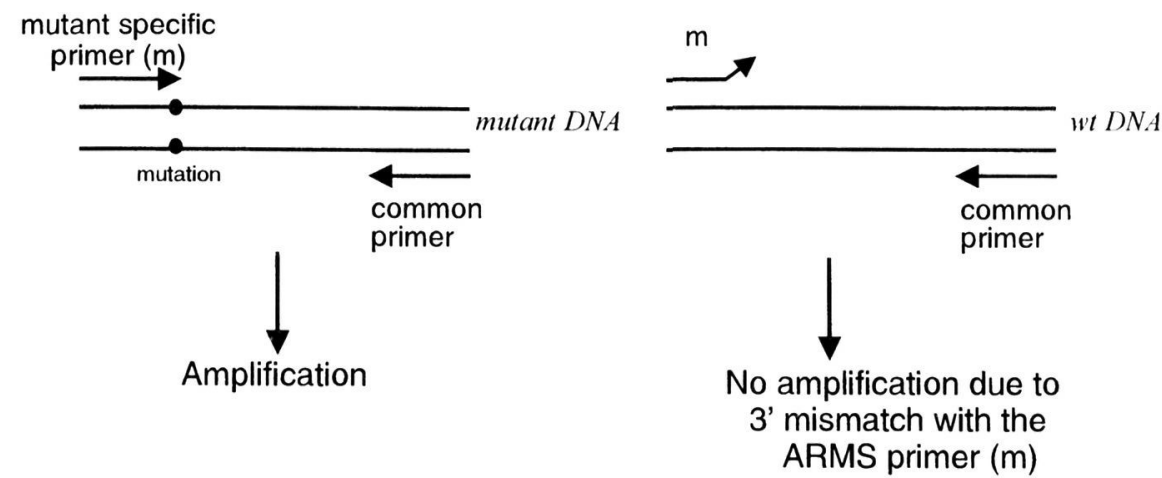

Figure 1. The principle of the ARMS assay. The 'M' (mutant) primers match the codon of interest at the final 3 ' with a specific base change, as in Table I. If the ' $\mathrm{M}$ ' primers perfectly match the DNA template then a product is formed. If the match is not perfect then no product will be made.

Table I. Specific base changes detected by the primers for codon 12 and 13 of K-ras in the ARMS assay.

\begin{tabular}{lllll}
\hline & \multicolumn{2}{c}{ codon } & 12 & \multicolumn{2}{c}{ codon } & 13 \\
\hline WT & GGT & gly & GGC & gly \\
1st base & CGT & arg & CGC & arg \\
& TGT & cys & AGC & ser \\
& AGT & ser & TGC & cys \\
2nd base & GTT & val & GTC & val \\
& GAT & asp & GAC & asp \\
& GCT & ala & GCC & ala \\
3rd base & GGA & gly & GGG & gly \\
& GGC & gly & GGT & gly \\
& GGG & gly & GGA & gly \\
\hline
\end{tabular}

Bold codons represent the sequences amplified in the ARMS K-ras tests used in this study.

ARMS assay (Fig. 1). Terminal base 3' matched oligonucleotide ARMS primers were used with K-ras intron specific primers to amplify individual base substituted K-ras sequences (10). In each K-ras specific amplification two additional pairs of primers (unrelated to the ras gene) resulted in the generation of two control bands. The control products were derived from the alpha anti-trypsin gene sequence ( $360 \mathrm{bp}$ product), and exon 4 of the cystic fibrosis gene (111 bp product). See Table I for the specific base changes detected by the primers used for codons 12 , and 13 in $\mathrm{K}$-ras.

\section{Results}

Four of 45 tumours analysed demonstrated K-ras mutations in codon 12 using RFLP, PCR followed by BstNI restriction of the product (see Fig. 2). The 45 specimens were also analyzed by ARMS analysis and the four K-ras mutations were confirmed (see Fig. 3). No G:C to A:T glycine to aspartic acid transitions were observed in codon 13 using the ARMS technique. All of the mutations were found to be at the second

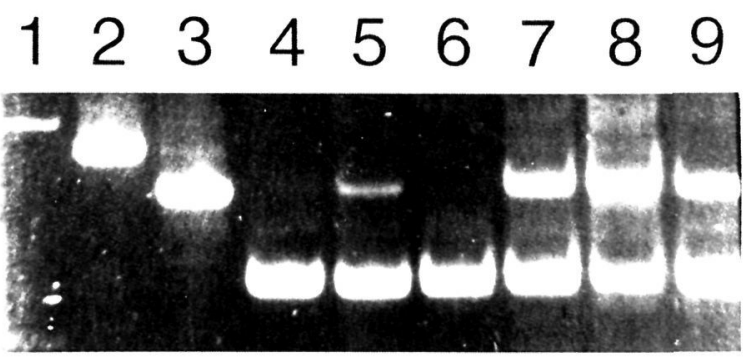

Figure 2. The PCR RFLP analysis. Lane 1, the HindIII molecular weight marker; Lane 2, uncut PCR product; Lane 3, cut PCR product from a cell line (SW480) which is a homozygous mutant for K-ras; Lanes 4, 5, 6, 7, 8 and 9 are tumour samples $56,45,16,32,47$ and 5 respectively. Tumours 56 and 16 are both wild-type, 45,32, 47 and 5 are all mutant at codon 12 in the $\mathrm{K}$-ras gene.

position of $\mathrm{K}$-ras codon 12. Two were G:C to T:A transversions resulting in an amino acid (aa) change from glycine to valine. One mutation was a $\mathrm{G}: \mathrm{C}$ to $\mathrm{A}: \mathrm{T}$ transition with a glycine to aspartic acid aa change while one other mutation was a G:C to $\mathrm{C}: \mathrm{G}$ transversion with an aa change from glycine to alanine (Table II). Three of the mutants were adenocarcinomas and one was an adenosquamous carcinoma. The forty-five NSCLC were analysed; $20 \%$ (3/15) of the adenocarcinomas and $14 \%(1 / 7)$ of the adenosquamous carcinomas were shown to have a mutated K-ras gene (9\% (4/45) of all NSCLC assayed) with no identifiable ras mutations in the squamous carcinomas.

\section{Discussion}

Mutations of the K-ras gene are frequently detected in a variety of neoplastic tissues including cancer of the pancreas, colon, thyroid, and lung. K-ras mutations appear to be an early event especially in human colorectal tumours and animal model systems $(2,3)$. Current diagnostic techniques for lung cancer detect only $25-40 \%$ of all lung tumours which are considered resectable and only $20 \%$ are found to have limited disease at the time of resection. However patients diagnosed with stage I tumours have a $40-80 \%$ survival rate after 


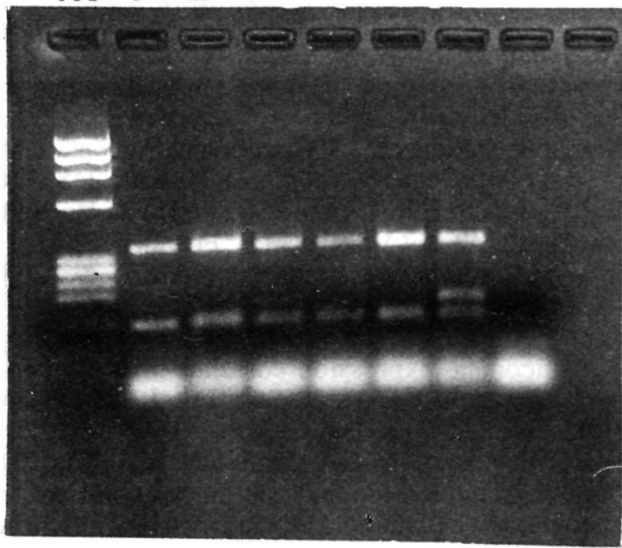

B
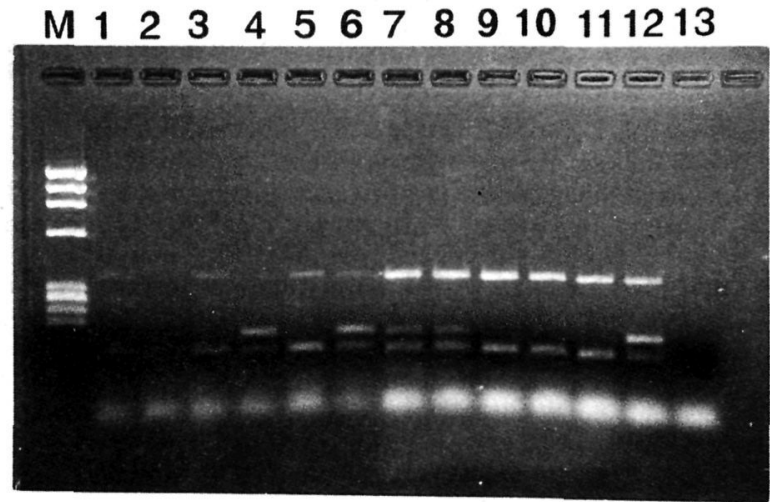

C

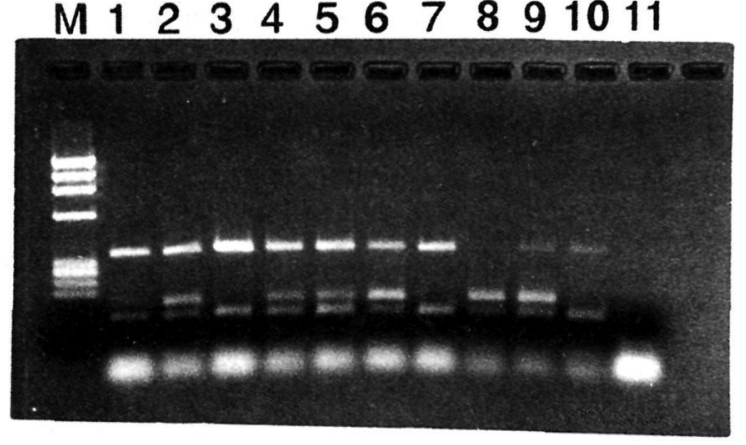

Figure 3. The ARMS analysis. (A), Use of the primer pair designed to test for codon $12 \mathrm{G}$ to A transitions which results in a glycine (gly) to asparagine (asp) amino acid change. Lane M (on all three gels) is $\Phi$ X174 HaeIII digest which has been used as a molecular weight marker. Lanes 1, 2, 3 and 4 are tumour samples 32, 45, 47 and 5 respectively, 47 is an asp mutant. Lane 5, a cell line (T3M4) which has a wild-type (WT) K-ras gene; lane 6, a known asp mutant cell line (SUIT2) used as positive control. Lane 7, a negative control run with no DNA (as is the last lane of these three gels). (B), i) Lanes 1-6 show the results of reactions using the primer pair designed to test for codon $12 \mathrm{G}$ to $\mathrm{C}$ transversions resulting in a gly to alanine (ala) amino acid change; ii) Lanes 7-13 show the results of reactions using the primer pair designed to test for codon $12 \mathrm{G}$ to $\mathrm{T}$ transversions resulting in gly to valine (val) amino acid changes. Lanes 1, 2, 3 and 4 represent tumours 32, 45,47 and 5 respectively, of which 5 contains an ala mutation. Lane 5, the negative control cell line T3M4; lane 6 , the positive control cell line SW1116, which is known to have an ala mutation. Lanes 7, 8, 9 and 10 represent the results from tumours $32,45,47$ and 5,32 and 45 are both val mutants. Lane 11 is the negative control cell line T3M4 and lane 12 is the positive control cell line PATI2 and known val mutant. (C), Lanes 1-3 use the primers from (A), lanes 4-7 use primer from the first half of (B, i), lanes 811 us primers from the second half of (B, ii). Lanes 3, 7 and 10 are the WT cell line T3M4, negative controls for each primer pair. Lanes 2, 6 and 9 are the mutant cell lines SUIT2 (asp mut), PATI2 (val mut) and SW1116 (ala mut) respectively. These are positive controls for each primer pair. Lanes 1, 4,5 and 8 are tumours $32,45,47$ and 5 respectively.

resection $(11,12)$. Thus rapid, early and accurate identification of mutations in the K-ras gene would aid in the diagnosis of lung cancer at a potentially curable stage of the disease. In this study we have used two PCR based techniques to detect mutations in the K-ras gene which we consider will simplify the process of detection without loss of sensitivity.

The PCR-RFLP assay detects any change in codon 12 of the K-ras gene and provides a useful primary screen as it can detect the majority (75-93\%) of K-ras mutations reported in the literature on lung cancer $(4,8,13-15)$. The technique uses a single base substitution in the upstream primer to create a BstNI restriction cleavage site (CCTGG) which is dependent on the two G's of codon 12 (GGT). Any change in the first two bases will destroy the cleavage site and the mutant would be detected as the product is not cleaved by BstNI. Any change in the third base of codon 12 of K-ras will be silent, since Glycine is encoded by any codon starting with GG. This technique is useful for screening large numbers of tumours

Table II. Mutations detected in the K-ras gene in NSCLC.

\begin{tabular}{ccclc}
\hline Tissue source & Base change & Codon 12 & Amino acid & Histology \\
\hline Normal & - & GGT & Glycine & - \\
47 & G $\rightarrow \mathrm{A}$ & GAT & Asparagine & Adenocarcinoma \\
5 & G $\rightarrow \mathrm{C}$ & GCT & Alanine & Adenocarcinoma \\
45 & G $\rightarrow \mathrm{T}$ & GTT & Valine & Adenocarcinoma \\
32 & G $\rightarrow \mathrm{T}$ & GTT & Valine & $\begin{array}{c}\text { Adenosquamous } \\
\text { carcinoma }\end{array}$ \\
\hline
\end{tabular}

The specific changes detected in the four bronchial carcinomas found to have mutations of the K-ras gene are shown. 
quickly and accurately. We demonstrated 4 mutations in the 45 bronchial tumours in this study using the PCR-RFLP method.

The second technique used to identify ras in this study was by ARMS, a PCR based technique which uses sequence specific primers to amplify an area of interest. Only primers with an exact matching sequence at the 3 ' terminal position will amplify the DNA from the tissue. This allows the simultaneous detection and elucidation of the mutation from the sequence of the primer which successfully amplified the DNA of the tissue. This method confirmed the 4 mutations found by PCR-RFLP and also demonstrated the specific base changes at these sites.

In this study no $\mathrm{G}$ to $\mathrm{A}$ transitions were found in codon 13 in the bronchial tumours whereas 4 mutations were found at codon 12. Three of four of the $\mathrm{K}$-ras mutations were found in adenocarcinomas which is consistent with the findings of Rodenhius and Slebos (14). However Mitsudomi et al (15) and Rosell et al (7) found that a third of all NSCLC examined were mutated at K-ras whereas our NSCLC results indicated only $9 \%$ contained ras mutations and $20 \%$ in adenocarcinomas.

These techniques are accurate, rapid and reproducible requiring only small quantities of DNA in order to give an unambiguous result. The RFLP PCR technique is effective for screening large numbers of tumour samples quickly. The ARMS assay is an unambiguous confirmation of mutations revealing specific sequence changes occurring at codon 12 of $\mathrm{K}$-ras. These techniques may have a potential role in the diagnosis and treatment of cancer.

$\mathrm{K}$-ras mutations have been successfully detected in stool, urine and sputum samples using labour intensive techniques which include phage cloning or Southern blotting of PCR products (12,16-18). The ARMS assay (Fox et al unpublished) has been shown to have at least a 1000 to 2000 fold sensitivity (i.e. 1 tumour cell detected in 1000 normal cells). Thus this technique has enormous possibilities in determining $\mathrm{K}$-ras mutations in high risk patients with lung cancer. We are currently pursuing this line of research.

\section{Acknowledgements}

This work was supported by the Lung Cancer Fund, Liverpool. The authors would like to thank Dr David Snary of the ICRF Applied Development Laboratory for his generous gift of control cell line DNAs used in the ARMS assay.

\section{References}

1. Parkin DM: Trends in lung-cancer incidence worldwide. Chest 96: $5 \mathrm{~s}-8 \mathrm{~s}, 1989$.

2. Bos JL: The ras gene family and human carcinogenesis. Mutation Res 195: 255-271, 1988.

3. Kumar R, Sukumar S and Barbacid M: Activation of ras oncogenes preceding the onset of neoplasia. Science 248: 1101-1104, 1990.

4. Bos JL, Fearon ER, Hamilton SR, Verlan-de Vries M, van Boom JH, van der Eb AJ and Vogelstein B: Prevalence of ras gene mutations in human colorectal cancers. Nature 327: 298-303, 1987.

5. Field JK, Yiagnisis M, Spandidos DA, Gosney JR, Papadimitriou K, Vaughan ED and Stell PM: Low-levels of ras p21 oncogene expression correlate with outcome in head and neck squamous-cell carcinoma. Eur J Surg Oncol 18: 168-176, 1992.

6. Kiaris H, Spandidos DA, Jones AS, Vaughan ED and Field JK: Mutations, expression and gnomic instability of the H-ras protooncogene in squamous cell carcinoma of the head and neck. $\mathrm{Br}$ J Cancer (In press).

7. Rosell R, Li S, Skacel Z, Mate JL, Maestre J, Canela M, Tolosa E, Armengol P, Barnadas A and Ariza A: Prognostic impact of mutated K-ras gene in surgically resected non-small cell lung cancer patients. Oncogene 8: 2407-2412, 1993.

8. Jiang W, Kahn SM, Guillem JG, Lu S and Weinstein B: Rapid detection of ras oncongenes in human tumors: Applications to colon, esophageal, and gastric cancer. Oncogene 4: 923-928, 1989.

9. Newton CR, Graham A, Heptinsall LE, Powell SJ, Summers C, Kalsheker N, Smith JC and Markham AF: Analysis of any point mutation in DNA - The amplification refractory mutation system (ARMS). Nucleic Acids Res 17: 2503-2516, 1989.

10. Stork P, Loda M, Bosar S, Wiley B, Poppenhusen K and Wolfe H: Detection of K-ras mutations in pancreatic and hepatic neoplasms by non-isotopic mismatched polymerase chain reaction. Oncogene 6: 857-862, 1991.

11. Kadri MA and Dussek E: Survival and prognosis following resection of primary non-small cell bronchogenic carcinoma. Eur J Cardio-Thoracic Surg 5: 132-136, 1991.

12. Mao L, Hruban RH, Boyle JO, Tockman M and Sidransky D: Detection of oncogene mutations in sputum precedes diagnosis of lung cancer. Cancer Res 54: 1634-1637, 1994.

13. Li S, Rosell R, Urban A, Font A, Ariza A, Armengol P, Abad A, Navas JJ and Monzo M: K-ras gene point mutation: A stable tumor marker in non-small cell lung carcinoma. Lung Cancer 11: 19-27, 1994

14. Rodenhius S and Slebos RJC: Clinical significance of ras oncogene activation in human lung cancer. Cancer Res 52: 2665s-2669s, 1992.

15. Mitsudomi T, Steinberg SM, Oie HK, Mulshine JL, Phelps R, Viallet J, Pass H, Minna JD and Gazdar AF: Ras-gene mutations in non-small cell lung cancers are associated with shortened survival irrespective of treatment intent. Cancer Res 51: 4999$5002,1991$.

16. Caldas C, Hahn SA, Hruban RH, Redston MS, Yeo CJ and Kern SE: Detection of K-ras mutations in the stool of patients with pancreatic adenocarcinoma and pancreatic ductal hyperplasia. Cancer Res 54: 3568-3573, 1994.

17. Sidransky D, Von Eschenbach A, Tsai YC, Jones P, Summerhayes I, Marshall F, Paul M, Green P, Hamilton SR, Frost P and Vogelstein B: Identification of p53 gene mutations in bladder cancers and urine samples. Science 252: 706-709, 1991.

18. Sidransky D, Tokino T, Hamilton SR, Kinzler KW, Levin B, Frost P and Vogelstein B: Identification of ras oncogene mutations in the stool of patients with curable colorectal tumors. Science 256: 102-105, 1992 